\title{
Gastric leiomyoblastoma
}

\author{
B. BOSE 1 AND J. CANDY \\ From the Greenwich District Hospital (Miller General Wing), London
}

SUMMARY This paper describes two cases of gastric leiomyoblastoma (bizarre smooth muscle tumour), one of them having evidence of metastases. Both patients remain well after seven years and three and a half years respectively. The literature is reviewed, and the clinical features, diagnosis, and treatment are discussed. The histological appearances are described in detail and an attempt is made to assess the criteria for the diagnosis of malignancy.

Smooth muscle tumours are the commonest nonepithelial tumours of the stomach, and the occurrence of both benign and malignant forms is higher in this organ than elsewhere in the gastrointestinal tract. They form $2.47 \%$ of all gastric tumours (Skandalakis, Gray, and Shepherd, 1960). Gastric leiomyomas and leiomyosarcomas of typical histological appearance have been recognized for many years. More recently another tumour of smooth muscle origin, a variant from the usual histological picture, has been identified not only in the stomach but also elsewhere in the body in relation to structures containing smooth muscle.

In 1960 Martin, Bazin, Féroldi, and Cabanne reported six cases of bizarre intramural myoid tumours of the stomach having unusual histological features, these features, in their opinion, being of diagnostic importance. In the light of this report, Stout (1962) reviewed 69 unusual stomach tumours, which previously he had recognized were smooth muscle tumours, but now realized had similar histological features to those found by Martin et al (1960) in their cases. He proposed the name 'leiomyoblastoma' as the vast majority were benign, but should there be any evidence of increased mitotic activity, such tumours could be designated as malignant leiomyoblastomas.

Increasing awareness of this type of tumour has resulted in several reports, and so far 111 cases

'Present address: Dreadnought Seamen's Hospital, London SE10. Received for publication 13 May 1970. have been recorded in the literature, the diagnosis in the majority being arrived at retrospectively (Table). The real incidence of this type of tumour has not yet been established, but it would appear that this is a rare lesion of the stomach which arouses considerable clinico-pathological interest. This has prompted us to record the following two cases of such a tumour, one benign and the other malignant, the latter not showing increased mitotic activity.

\begin{tabular}{|c|c|}
\hline Case Report & $\begin{array}{l}\text { Total No. } \\
\text { of Cases }\end{array}$ \\
\hline $\begin{array}{l}\text { Single Cases } \\
\text { Fontaine, Lang, Hiebel, and Philippe (1964); Gui } \\
\text { and Féroldi (1965); Gupta and Chandler (1965); } \\
\text { Herrington (1966 and 1968); Kay and Still (1969) } \\
\text { Kelsey (1966); Sautot, Tommasi, and Vauzelle } \\
\text { (1965); Sebgal, Nayak, Hingorani, and Bapna } \\
\text { (1966); Sommariva and De Feo (1963); Sinnreich } \\
\text { et al (1966); Wolf (1968); Woodington and } \\
\text { Carter (1966); Yarington and Cook (1962) }\end{array}$ & 14 \\
\hline $\begin{array}{l}\text { Two Cases } \\
\text { Kay (1964); Schofield and Fox (1965); Saubier } \\
\text { (1969) }\end{array}$ & 6 \\
\hline $\begin{array}{l}\text { Three Cases } \\
\text { Kubo, Kiyoshi, and Takayoshi (1965); Martin, } \\
\text { Tommasi, Vauzelle, and Byron (1965) }\end{array}$ & 6 \\
\hline $\begin{array}{l}\text { More than Three Cases } \\
\text { Martin et al (1960); Stout (1962); Tallqvist et al } \\
\text { (1967) }\end{array}$ & 85 \\
\hline Total & 111 \\
\hline
\end{tabular}

Table Case reports of gastric leiomyoblastoma 


\section{Case Histories}

CASE 1 (A.F.)

A 53-year-old male attended the Surgical Clinic in June 1962, with a two-month history typical of duodenal ulcer. His past history was unremarkable, and a physical examination was normal. All investigations, including gastric analysis, barium meal, and cholecystogram, were normal. He responded satisfactorily to a course of medical treatment. Six months later the symptoms recurred, and investigations repeated on this occasion were once again found to be perfectly normal. He received another course of medical treatment, but failed to respond satisfactorily. An exploratory laparotomy was advised and undertaken in January 1963. At operation there was no evidence of peptic ulcer, biliary tract disease, or pancreatitis. However, a subserous stomach tumour measuring $3.5 \times 2.5 \mathrm{~cm}$ was found in the pyloric region. The tumour was excised and an appendectomy performed. He made an uneventful recovery from the operation, and remained well for a year. Then the original symptoms recurred again, and in August 1965 he had to be admitted as an emergency with a four-day history of upper abdominal pain which became severe 24 hours before admission. He settled down rapidly with conservative treatment, and a barium meal examination a few days later showed a constant deformity of the duodenal cap, probably due to chronic duodenal ulceration. In view of the history and radiological finding, a second laparotomy was undertaken and the presence of a posterior duodenal ulcer was confirmed. There was no recurrence of the stomach tumour, but the scar of the previous tumour excision could be recognized easily.Vagotomy and pyloroplasty were performed. He made an uneventful recovery and has remained well since.

\section{Pathology}

The specimen is a subserous stomach nodule. It consists of a soft, irregular piece of pinkish tissue, $3.5 \times 2.5 \times 1 \mathrm{~cm}$, covered on one surface by peritoneum.

Histologically this is a moderately cellular tumour composed mainly of rounded or polygonal cells. The cytoplasm is very faintly granular and is eosinophilic. The nuclei vary little in size and have a faint vesicular structure. Nucleoli are not prominent. No mitoses are seen. Many cells show a partial or completely clear zone around the nuclei. Many small vessels are present. This tumour is a leiomyoblastoma or 'bizarre smooth muscle tumour of the stomach' (Fig. 1).

CASE 2 (F.W.)

A 75-year-old male was admitted to the medical ward in September 1966 for investigation of anaemia. He complained of progressive weakness and shortness of breath for five months, and had noticed swelling of his ankles two weeks before admission. There was no history of anorexia, abdominal pain, or altered bowel habit. The positive findings on physical examination were extreme pallor, bilateral pitting oedema of ankles, and a soft, non-tender smooth liver palpable $4 \mathrm{~cm}$ below the costal margin. The haemoglobin was $4.3 \mathrm{~g}$ and haematological studies revealed severe iron-deficiency anaemia. The occult blood in the stool was strongly positive. Chest radiology showed no abnormalities. A barium meal showed a large filling defect in the distal half of the stomach, but there was no evidence of obstruction to stomach emptying (Fig. 2).

A transfusion of $1,000 \mathrm{ml}$ of packed cells and a total dose infusion of iron raised the haemoglobin to $9 \cdot 2 \mathrm{~g}$. His general condition was too good for gastric carcinoma and therefore it was suspected that the lesion was a large leiomyoma. At operation a large tumour, $8 \mathrm{~cm}$ in diameter, protruding from the posterior wall of the pyloric antrum into the transverse mesocolon was found. The tumour was partly solid and partly cystic (Fig. 3). No protrusion of the tumour was palpable in the lumen of the stomach, but a crater $2 \mathrm{~cm}$ in diameter could be felt through the anterior stomach wall. The tumour was mobile with the

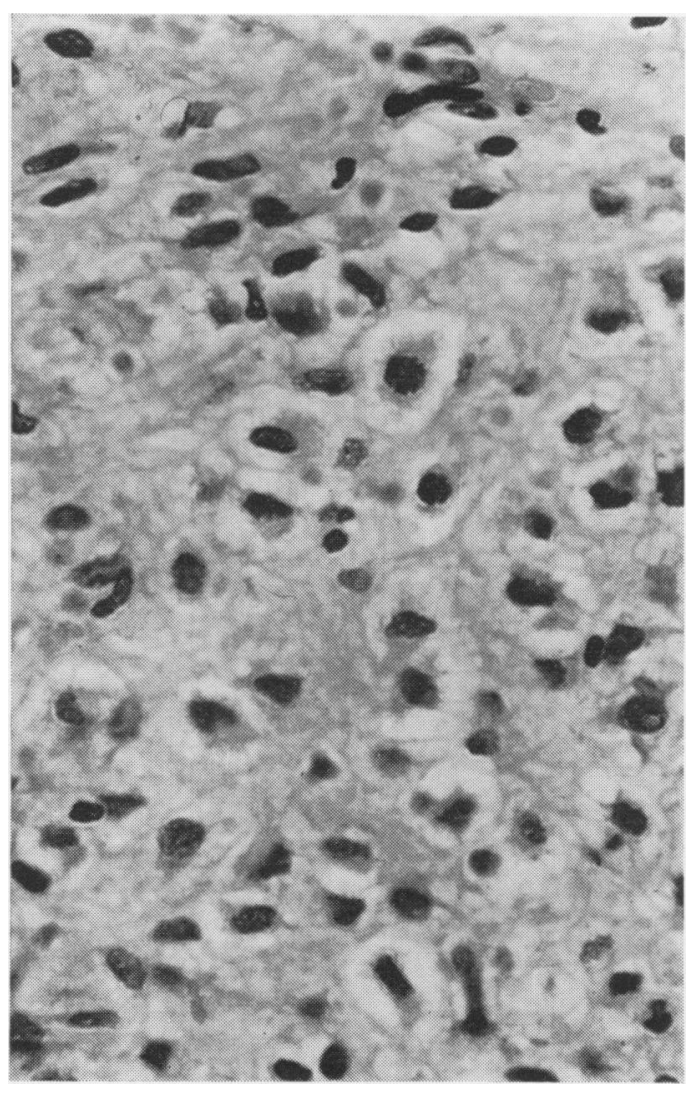

Fig. 1 Case 1. Rounded and polygonal tumour cells with perinuclear halo ( $H$ and $E \times 400)$. 
stomach and did not infiltrate any of the adjacent organs other than the mesocolon. The liver contained multiple small blue-black swellings which appeared to be small cysts. The stomach, with the tumour, was easily mobilized and dissected out of the mesocolon, preserving the middle colic artery. A standard Billroth J gastrectomy was performed and it was possible to resect the stomach well above the tumour. One of the nodules from the liver was removed for histology.

The patient made an uneventful recovery and was discharged 18 days after the operation with a haemoglobin of $10 \cdot 3 \mathrm{~g}$. He has attended the hospital regularly for follow up since discharge and has remained well. However, in September 1969-while symptom-free and clinically not anaemic - a vague mass was noted in the upper epigastric region. Four months later the mass became more obvious (approximately $5 \mathrm{~cm}$ in diameter) but clinically it was not possible to ascertain whether the mass was a liver secondary or a local recurrence. A liver scan showed the mass to indent the inferior margin of the liver, but it was uncertain whether the mass was intra- or extrahepatic. A barium meal showed a normally

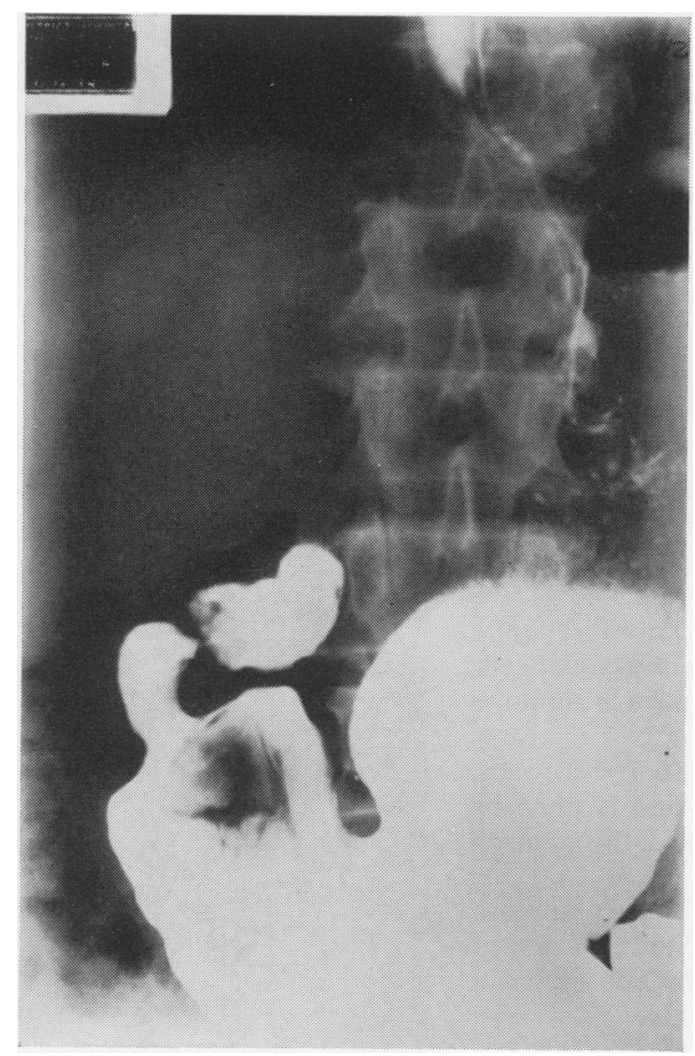

Fig. 2 Case 2. Barium meal radiograph showing typical filling defect in the pyloric antrum. functioning Billroth I gastrectomy, and therefore it was presumed that the epigastric mass was a liver metastasis. When last seen in March 1970 the patient was symptom free, had a haemoglobin of $12 \mathrm{~g}$, normal liver function tests, and the epigastric mass was still palpable. It was not thought justifiable to subject him to a needle biopsy of the liver.

\section{Pathology}

The specimen consists of a partial gastrectomy, 11 $\mathrm{cm}$ along the lesser curve and $27 \mathrm{~cm}$ along the greater. Just below the lesser curvature, on the posterior wall, the mucosal surface is raised by a soft rubbery mass over an area of $5 \times 3 \mathrm{~cm}$, and shows two areas of ulceration (Fig. 4). The mucosa is not fixed. On the serosal surface there is a thinwalled cyst, $6 \mathrm{~cm}$ in diameter, which is in continuity with the main mass (Fig. 3). The cyst is unilocular and filled with straw-coloured fluid containing loose pieces of soft greyish-white tissue. The cut surfaces of the mass are soft, have a brownishwhite opaque appearance, and show irregularsized lobules separated by narrow fibrous bands.

This is a highly cellular tumour, the majority of

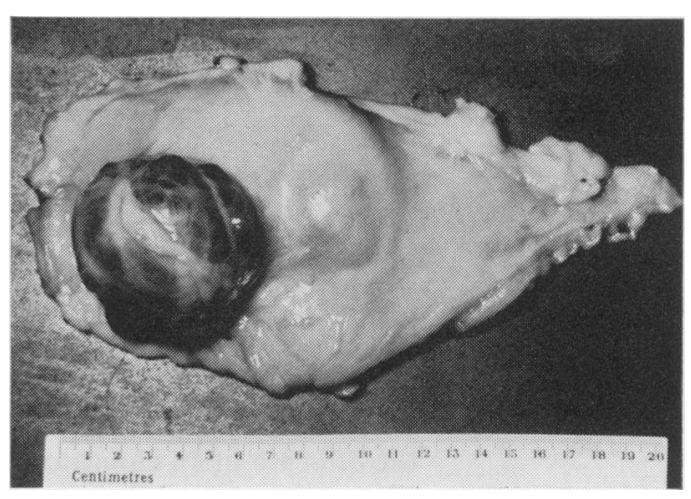

Fig. 3 Case 2. Posterior serosal aspect of gastrectomy specimen showing projection of the tumour which is partly cystic.

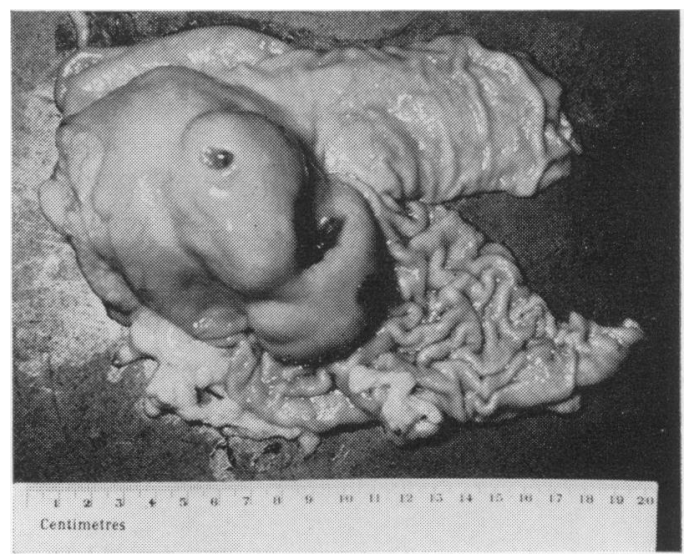

Fig. 4 Case 2. Note protrusion of tumour into the gastric lumen and two mucosal ulcers. 


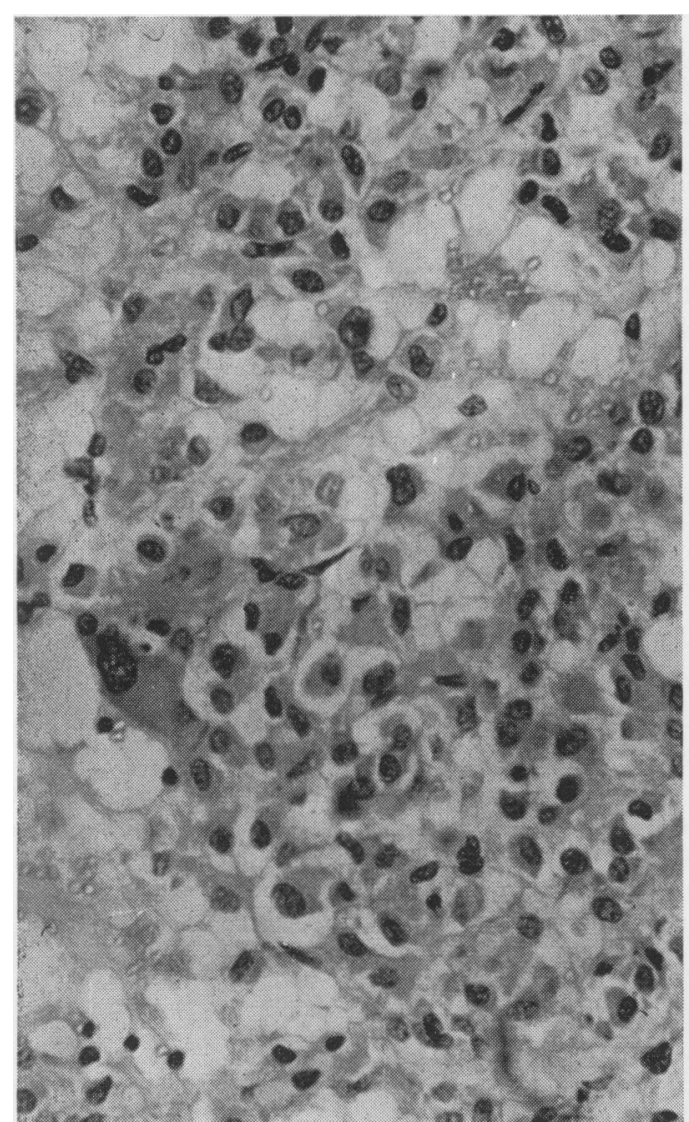

Fig. 5 Case 2. Cell variation and perinuclear halo ( $H$ and $E \times 250)$.

the cells being round or polygonal, and not showing great variation in size. There are areas where the cells are more elongated and spindle-shaped. The nuclei are round or ovoid, varying a little in size and have a vesicular structure. They are not hyperchromatic and do not have prominent nucleoli. Small numbers of mitotic figures are present. The cytoplasm is eosinophilic, quite deeply in some cells. Many of the polygonal cells show a clear zone, partial or complete around the nuclei (Figs. 5 and 6).

The soft brown nodule $(1 \times 0.5 \times 0.5 \mathrm{~cm})$ from the liver is partially cystic and is lined by cells of similar appearance to those of the stomach tumour (Fig. 7).

This tumour has the features of 'bizarre smooth muscle cell tumour' described by Stout. In view of the liver metastases, it should be considered a malignant leiomyoblastoma.

\section{Discussion}

The natural history of leiomyoblastoma appears to be different from other types of smooth muscle gastric tumours. The lesion is more common in

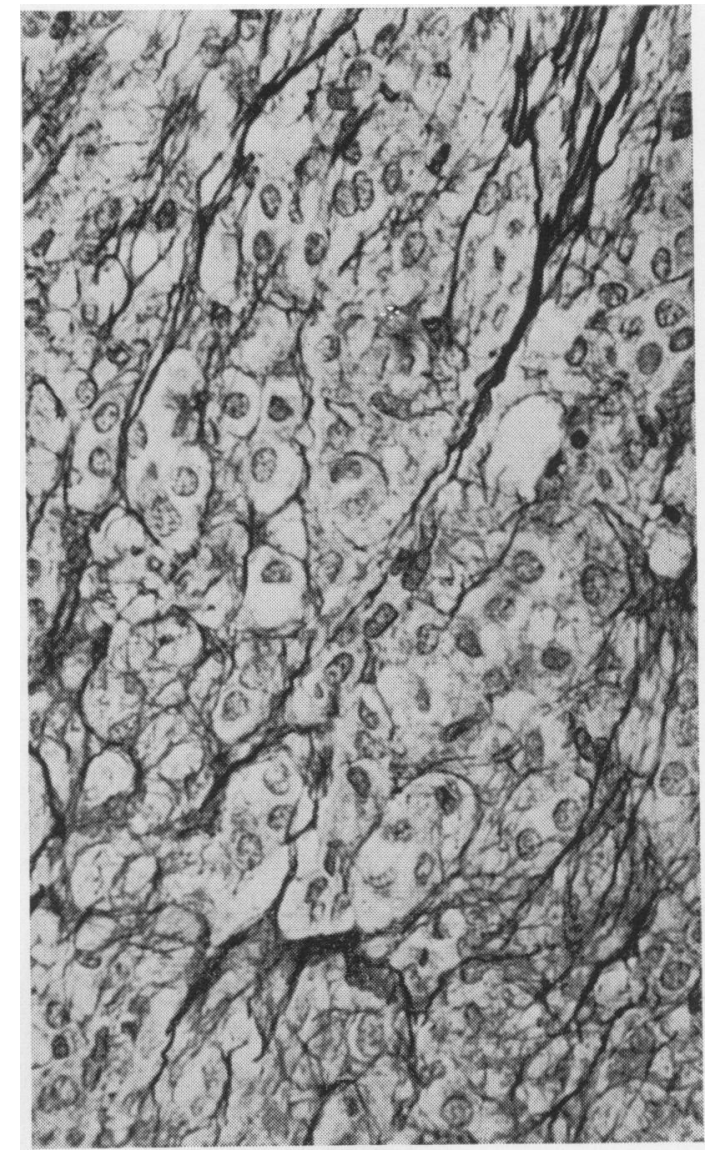

Fig. 6 Case 2. Reticulin structure and typical tumour cells (Silver stain $\times 250)$.

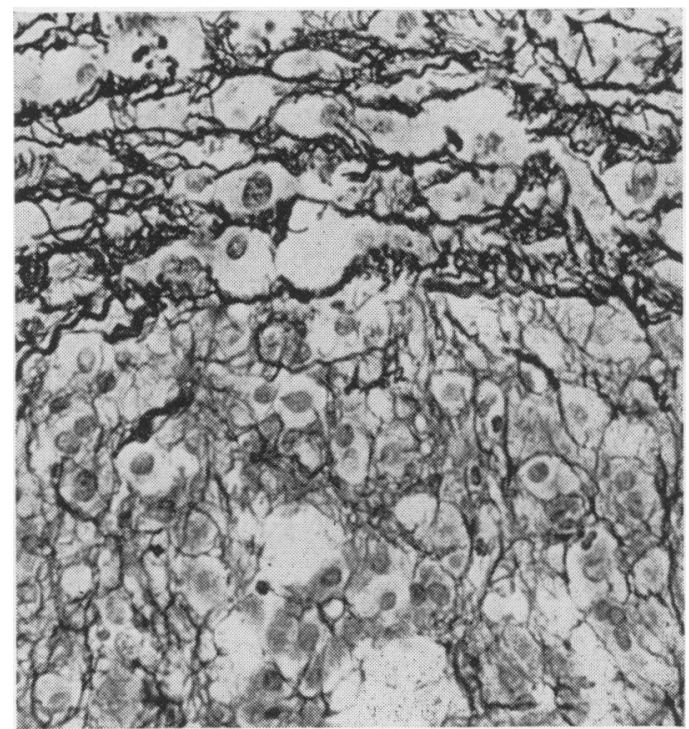

Fig. 7 Case 2. Section of liver deposit showing compressed liver tissue at the top and tumour below. The tumour cells have the same features as in Figure 6 (Silver stain $\times 250$ ).

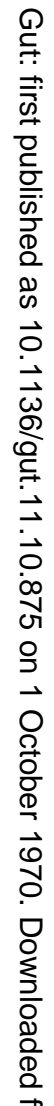


men than women $(2: 1)$ and two-thirds of the reported cases have occurred in people over 40 years old. In the series reported by Stout (1962) the youngest female patient was 17 and the youngest male 23 years old.

The clinical presentation is no different from other smooth muscle tumours; haemorrhage with or without anaemia is the most common presenting symptom. One of the patients reported by Martin et al (1960) was admitted to hospital in a collapsed state due to massive melaena. Other recorded modes of presentation are pain and epigastric discomfort, palpable mass, loss of weight, and symptoms of peptic ulcer, in that order. The presence of an epigastric mass with or without anaemia in a patient otherwise well may arouse the suspicion of a non-malignant smooth muscle tumour of the stomach. A few unusual clinical features of leiomyoblastoma have been described. Stout (1962) and Schofield and Fox (1965) each reported a case where size, consistency, and location of the tumour led to a preoperative clinical diagnosis of pancreatic cyst. Sinnreich, Friedmann, Dasco, and Stern (1966) document a case where location and mobility of the tumour led to the diagnosis of pedunculated uterine fibroid. Invasion of the gastric serosa produced an acute and massive peritoneal haemorrhage in the case described by Kelsey (1966).

Gastroscopy may exclude carcinoma or peptic ulceration, but the endoscopic appearances of leiomyoblastoma are in no way different from other intramural tumours, the classical appearance being that of a smooth localized tumour of rather pale colour with the mucosa stretched smoothly over it. When the mucosa has ulcerated over the most prominent part of the tumour the appearance has been likened to the uterine cervix (Jones, Gummer, and Lennard-Jones, 1968).

The radiological appearances are typically those of any intramural tumour, namely, a well defined filling defect or a sharp mucosal angle at the edge of an intragastric protrusion. Should mucosal ulceration follow with necrosis of the tumour then the contrast media may enter the necrotic cavity producing a characteristic 'bull's eye' pattern (Oschner and Janetos, 1965). In the majority of cases, unlike carcinoma, there is no disturbance of peristalsis (Stout, 1962).

The most common location of the leiomyoblastoma is in the pyloric antrum, followed by the body of the stomach. One case has been described high in the lesser curve (Guillet and Féroldi, $1965)$. The size is variable $(0.5-20 \mathrm{~cm})$. The largest tumour reported measured $35 \times 20 \times 8 \mathrm{~cm}$ (Wolf, 1968). The lesion is usually single, but multiple lesions have been reported (Tallqvist, Salmela, and Lindström, 1967). The majority are intramural with a greater tendency to grow towards the lumen, where in time the overlying mucosa becomes eroded and ulceration with bleeding supervenes. They can also form hourglass tumours or have a mainly exogastric extension into the gastrohepatic or gastrocolic omentum as in case 2 . In $4 \%$ of cases reported the tumour was pedunculated. Most tumours are described as softer than leiomyomas (Stout, 1952). Cystic degeneration is not uncommon, and cut section of the tumour may show areas of necrosis, haemorrhage, or both. The naked-eye appzarance is therefore extremely variable.

The histological features are highly characteristic. The majority of the cells are rounded or polygonal, unlike the usual elongated smooth muscle cells. The rounded cells have eosinophilic faintly granular cytoplasm arranged in regular bunches or irregular strings (Martin et al, 1960). Occasionally continuity can be traced between these rounded cells and leiomyoblasts that appear more normal. The most important feature is the presence of a clear zone completely or partially surrounding the nucleus which is usually spherical but often flattened, giving the cells an 'owl's eye' appearance (Schofield and Fox, 1965). This clear zone gives negative staining reactions for mucus, glycogen, and lipid (Stout, 1962). Electron microscopic studies by Kay and Still (1969) have shown that the vacuolated appearance of the cells is characteristic and sufficient to distinguish them morphologically from leiomyosarcoma and leiomyoma. Histological interpretation can be difficult unless one is aware of the bizarre appearance of this tumour. Stout found that 108 diagnoses were suggested for 69 cases of leiomyoblastoma, out of which no diagnosis was offered for 13 cases. Leiomyoma and leiomyosarcoma were the commonest diagnoses made; neurogenic tumour was the next most common, followed by vascular tumours. It is interesting to note that in only 30 of the 108 diagnoses suggested was it realized that there was smooth muscle present, and even then there was a sharp division of opinion as to whether the tumours were benign or malignant. Another retrospective study of 10 cases by Tallqvist et al (1967) again showed that this lesion had been misdiagnosed.

Is this tumour malignant? The vast majority pursue a benign course. Martin et al (1960) reported one malignant tumour out of six cases; Stout (1962) two out of 69; and Tallqvist et al (1967) one out of 10 cases. In 111 cases so far reported six have been classified as malignant, and, when our case is added to the list, the incidence of malignancy becomes 6 percent. In the absence of metastases, the number of mitoses may be an indication of malignancy, and it has been suggested by Herrington (1968) that if a mitotic figure rate of more than four per 50 random high-power fields is seen, the tumour should be considered malignant. A case described by Tallqvist et al(1967), which had only two mitotic figures per 50 random high-power fields, was later proved malignant when liver secondaries were found at a subsequent laparotomy for endometriosis 15 months later. In six of Stout's cases three to 19 mitoses were found, and two of these subsequently proved 
malignant by the development of metastases. In other areas of the same tumours the mitotic rate did not exceed 2. The authors do not therefore share the view expressed by Herrington (1968). It appears that metastases grow very slowly, and, if not detected at the time of laparotomy, the natural course of the disease will indicate at a future date if the tumour was malignant.

Surgery seems to be the treatment of choice and should be carried out if the tumour is removable, even if metastases are present, as indeed was done in our case 2 . Saubier (1969) successfully resected a leiomyoblastoma from the stomach and at the same time removed part of the right lobe of the liver which was the site of a metastasis. In spite of the large size and extragastric extension of some of the reported cases, resection was relatively easy, as this tumour does not stimulate inflammatory or fibroblastic reaction. Wedge resection or enucleation for small tumours is justified, provided they prove benign on frozen section examination. It is therefore important that this lesion be recognized, because its biological behaviour and prognosis differ so markedly from those of gastric sarcoma and carcinoma. The authors felt it was worthwhile to call this lesion (case 2) to the attention of those who may perhaps encounter it in the future.

We are grateful to $\mathrm{Dr}$ G. Thomas, consultant pathologist, for drawing our attention to this tumour, and for his help and advice in preparing this article.

\section{References}

Fontaine, R., Lang, G., Hiebel, G., and Philippe, E. (1964). A propos d'un cas de leiomyoblastoma de l'estomac. Arch. Mal. Appar. dig., 53, 785-792.

Guillet, R., and Féroldi, J. (1965). Un cas de tumeur myoỉde intra-murale de l'estomac. Lyon chir., 61, 573-574.
Gupta, R. K., and Chandler, J. P. (1965). Leiomyoblastoma of stomach: case Report. Ann. Surg., 161, 562-564.

Herrington, J. L., Jr. (1966). Leiomyoblastoma of the stomach. Amer. J. Surg., 111, 569-572.

Herrington, J. L., Jr. (1968). Gastric leiomyoblastoma. Amer. Surg., 34, 681-686.

Jones, F. A. (1968). Clinical Gastro-Enterology, 2nd ed. Blackwell, Oxford and Edinburgh.

Kay, S. (1964). Smooth muscle tumors of the stomach. Surg. Gynec. Obstet., 119, 842-846.

Kay, S., and Still, W. J. S. (1969). A comparative electron microscopic study of a leiomyosarcoma and bizarre leiemyoma (leiomyoblastoma) of the stomach. Amer. J. Clin. Path., 52, 403-413.

Kelsey, J. R., Jr. (1966). Leiomyoblastoma of the stomach presenting as acute intraperitoneal hemorrhage. Gastroenterology, 51, 539-541.

Kubo, T., Kiyoshi, N., and Takayashi, H. (1965). Bizarre leiomyoblastoma of stomach. Jap. J. Cancer Clin., 11, 643-646.

Martin, J. F., Bazin, P., Féroldi, J., and Cabanne, F. (1960). Tumeurs myoldes intra murales de l'estomac, considération microscopique á propos de 6 cas. Ann. Anat. path., 5, 484-497.

Martin, J. F., Tommasi, M., Vauzella, J. L., and Byron, P.A. (1965). A propos des 'tumeurs myoides' intra-murales de l'estomac. (Exposé de trois nouveaux cas.) Arch. Anat. path., 13, 9-13.

Oshsner, J. F., and Janetos, G. P. (1965). Benign tumours of stomach. J. Amer. med. Ass., 191, 881-887.

Saubier, E. (1969). A propos de deux observations de tumeurs myoides de l'estomac dont une dégénérrée ayant nécessité une hepatectomie droite élargie: resultant eloigne. Lyon chir., 65, 128-132.

Sautot, J., Tommasi, M., and Vauzelle, J. L. (1965). Tumeur 'myolde' intra-murale de l'estomac. Lyon chir., 61,567-572.

Schofield, P. F., and Fox, H. (1965). Leiomyoblastoma of stomach. Brit. J. Surg., 52, 928-930.

Sehgal, B., Nayak, N. C., Hingorani, V., and Bapna, B. C. (1966). Bizarre leiomyoblastoma of the stomach. Indian J. Path. Bact., 9, 90-96.

Sinnreich, M., Friedman, R., Dasco, M. R., and Stern, W. (1966). Bizarre gastric leiomyoblastoma simulating a pedunculated uterine fibromyoma. Obstet. and Gynec., 27, 690-694.

Skandalakis, J. E., Gray, S. W., and Sheperd, D. (1960). Smooth muscle tumors of the stomach. (Collective review.) Int Abstr. Surg., 110, 209-226.

Sommariva, V., and De Feo, G. (1963). Su di un particolare reperto istologico di leiomioma gastrico (leiomioma atipico). Minerva chir., 18, 574-583.

Stout, A. P. (1962). Bizarre smooth muscle tumors of the stomach. Cancer (Philad.), 15, 400-409.

Tallqvist, G., Salmela, H., and Lindstrom, B. L. (1967). Leiomyoblastoma of the stomach. A clinico-pathological study of 10 cases. Acta path. microbiol. scand., 71, 194-202.

Wolf, J. S. (1968). Massive leiomyoblastoma of the stomach. Arch. Surg., 96, 284-288.

Woodington, G. F., and Carter, K. L. (1966). Leiomyoblastoma of the stomach. Wis. med.J., 65, 173-174.

Yarington, C. T., Jr., and Cook, M. D. (1962). Bizarre leiomyoma (leiomyoblastoma). Report of a case. J. int. Coll. Surg., 38, 195-199. 